\title{
Crystal structure of an FIV/HIV chimeric protease complexed with the broad-based inhibitor, TL-3 Holly Heaslet ${ }^{1}$, Ying-Chuan Lin ${ }^{2}$, Karen Tam ${ }^{2}$, Bruce E Torbett ${ }^{3}$, John H Elder ${ }^{2}$ and C David Stout*2
}

Address: ${ }^{1}$ Pfizer Global Research \& Development, 2800 Plymouth Rd., Ann Arbor, MI 48105, USA, ${ }^{2}$ Department of Molecular Biology, The Scripps Research Institute, 10550 N. Torrey Pines Rd., La Jolla, CA 92037, USA and ${ }^{3}$ Department of Molecular \& Experimental Medicine, The Scripps Research Institute, 10550 N. Torrey Pines Rd., La Jolla, CA 92037, USA

Email: Holly Heaslet - hheaslet@scripps.edu; Ying-Chuan Lin - ylin@scripps.edu; Karen Tam - ktam@scripps.edu; Bruce E Torbett - betorbet@scripps.edu; John H Elder - jelder@scripps.edu; C David Stout* - dave@scripps.edu

* Corresponding author

Published: 09 January 2007

Retrovirology 2007, 4:I doi:10.1 186/1742-4690-4-I

This article is available from: http://www.retrovirology.com/content/4/I/I

(c) 2007 Heaslet et al; licensee BioMed Central Ltd

This is an Open Access article distributed under the terms of the Creative Commons Attribution License (http://creativecommons.org/licenses/by/2.0), which permits unrestricted use, distribution, and reproduction in any medium, provided the original work is properly cited.

\begin{abstract}
We have obtained the $1.7 \AA$ crystal structure of FIV protease (PR) in which 12 critical residues around the active site have been substituted with the structurally equivalent residues of HIV PR (I2X FIV PR). The chimeric PR was crystallized in complex with the broad-based inhibitor TL-3, which inhibits wild type FIV and HIV PRs, as well as I2X FIV PR and several drug-resistant HIV mutants [1-4]. Biochemical analyses have demonstrated that TL-3 inhibits these PRs in the order HIV PR > I2X FIV PR > FIV PR, with $K_{i}$ values of $1.5 \mathrm{nM}, 10 \mathrm{nM}$, and $4 \mathrm{I} \mathrm{nM}$, respectively [2-4]. Comparison of the crystal structures of the TL-3 complexes of I2X FIV and wild-typeFIV PR revealed theformation of additinal van der Waals interactions between the enzyme inhibitor in the mutant PR. The I2X FIV PR retained the hydrogen bonding interactions between residues in the flap regions and active site involving the enzyme and the TL-3 inhibitor in comparison to both FIV PR and HIV PR. However, the flap regions of the I2X FIV PR more closely resemble those of HIV $P R$, having gained several stabilizing intra-flap interactions not present in wild type FIV PR. These findings offer a structural explanation for the observed inhibitor/substrate binding properties of the chimeric PR.
\end{abstract}

\section{Background}

Feline immunodeficiency virus (FIV), a member of the lentivirus family, is a useful model for developing intervention strategies against lentiviral infection [5-7]. We aim to better understand the molecular basis of HIV-1 and FIV protease (PR) substrate and inhibitor specificities in order to develop broad-spectrum protease inhibitors that will inhibit both wild type and drug-resistant proteases. This approach has led to the development of TL-3, an inhibitor that is capable of inhibiting FIV, SIV, HIV-1 and several HIV-1 drug-resistant strains ex vivo [1-3], and other potential inhibitors with broad efficacy [8-10]. FIV PR, like HIV-1 PR, is a homodimer, but each monomer is comprised of 116 amino acids, as opposed to 99 amino acids for HIV-1 PR. The structure of FIV PR has been determined and compared to that of HIV-1 PR [11-13]. FIV PR, particularly in the active core region, is very similar to HIV-1 PR but only shares 27 identical amino acids $(23 \%$ identical at amino acid level) and exhibits distinct substrate and inhibitor specificity [11,14-17]. FIV and HIV-1 
PR each prefer their own matrix-capsid (MA-CA) junction substrate and FIV PR prefers a longer substrate than HIV1 PR. Current clinical drugs against HIV-1 PR are poor inhibitors for FIV PR, primarily due to a smaller S3 substrate binding site in FIV PR which restricts binding of these drugs $[2,3]$.

FIV PR is responsible for processing the FIV Gag and GagPol polyproteins into 10 individual functional proteins[18]. Although the overall order of proteins in the Gag-Pol polyprotein in FIV and HIV-1 is similar, distinctions are also evident. HIV-1 Gag-Pol has an additional small spacer protein, $\mathrm{p} 1$, between nucleocapsid (NC) and p6 while the equivalent region in FIV is a single p2 peptide. In addition, HIV-1 lacks dUTPase (DU), which is encoded between reverse transcriptase (RT) and integrase (IN) within the Pol polyprotein in FIV. FIV PR, similar to HIV-1 PR, regulates its own activity through autoproteolysis at 4 cleavage sites in PR [12].

In both HIV-1 and FIV, the sequence of Gag and Gag-Pol precursor processing is highly regulated and critical for producing mature viruses for infection and replication [4,19-21]. Thus, PR is an attractive target for development of antiretroviral drugs. Protease inhibitors have drastically slowed the progression of disease and reduced the mortality rate in HIV-1 infected patients [22-25]. However, the high error rate of reverse transcriptase (RT) and high levels of viral replication, combined with lack of adherence to medication regimens, have led to the development of drug-resistant strains. Additional strategies are therefore needed for drug design to target cross-resistant PR variants.

The properties of FIV PR and HIV-1 PR have been compared to better understand the molecular basis of retroviral PR substrate and inhibitor specificity. In previous studies, up to 24 amino acid residues in and around the active site of FIV PR were substituted at equivalent positions of HIV-1 PR and the specificity of mutant PRs was examined in vitro $[2,4,15-17]$. Substrate specificity of mutant FIV PRs was analyzed by examining cleavage efficiency on peptides representing HIV-1 and FIV cleavage sites. Inhibitor specificity of mutant PRs was assessed by measuring $\mathrm{IC}_{50} / K_{\mathrm{i}}$ values of potent HIV-1 PR inhibitors. These experiments have revealed that some mutants, such as $\mathrm{I} 37^{32} \mathrm{~V}$ in the active core, $\mathrm{N} 55^{46} \mathrm{M}, \mathrm{M} 56^{47} \mathrm{I}$ and V5950I in the flap region, and $\mathrm{L} 97^{80} \mathrm{~T}, \mathrm{I} 98^{81} \mathrm{P}, \mathrm{Q} 99^{82} \mathrm{~V}$, and $\mathrm{P} 100^{83} \mathrm{~N}$, and $\mathrm{L} 101^{84} \mathrm{I}$ in the "90s loop" region, retained comparable activity against FIV substrates while substantially changing substrate and inhibitor specificities toward that of HIV-1 PR (residue numbers for HIV PR indicated in superscript) (Fig. 1) [15,17]. Partial changes, both in inhibitor and substrate binding, were observed with over 40 chimeric PRs generated in the previous studies [4]. The most critical residues are embodied in a mutant containing 12 amino acid substitutions (referred to elsewhere as "12S FIV [4] and the studies reported here utilize this chimeric PR.

In order to better understand the molecular basis for the chimeric phenotypes described above, we have analyzed the crystal structure of a 12X FIV/HIV chimeric PR in complex with TL-3 and compared that structure to FIV and HIV wild type PRs in complex with the same inhibitor. The results show little alteration in the hydrogen bonding network formed between residues in the active site and flap regions of PR and the inhibitor. However, there is an increase in packing contacts formed between the P1 phenyl group of TL-3 and residues in the "90s loop" of the chimeric PR which involve 5 of the 12 mutations. These interactions help to explain the increase in potency of TL3 against the 12X FIV PR relative to FIV PR. Additional mutations in 12X FIV PR localized to the flap regions of PR result in the formation of contacts within and between monomers, which may be related to changes in substrate processing efficiency.

\section{Results \\ Two fold symmetric I2X FIV PR dimer binds C2 symmetric TL-3}

To better understand the structural basis for the changes in substrate processing and efficiency as well as inhibitor specificity in the 12X FIV PR mutant, we determined the 1.7 ̊ crystal structure of $12 X$ FIV PR in complex with TL-3. The 12X FIV PR-TL3 complex crystallized in the space group $P 3_{1} 21$ with a monomer in the asymmetric unit and the $\mathrm{C}_{2}$ axis of the protease dimer coincident with a crystallographic 2-fold (Table 1). As a result, the structure of the complex is an average of the two half-sites. Similarly, TL3 was bound in the active site of the 12X FIV PR with its $\mathrm{C}_{2}$ axis of symmetry coincident with the crystallographic 2-fold and, therefore, was modeled as one half of the $\mathrm{C}_{2}$ symmetric compound.

The network of hydrogen bonds between TL-3 and residues in the catalytic loop and flap region of the 12X FIV protease is essentially identical to that observed in the HIV PR-TL-3 and FIV PR-TL-3 complexes previously determined (Fig. 2) $[13,26]$. This hydrogen bonding network is mediated by four central water molecules and another coincident on the $\mathrm{C}_{2}$ axis, and includes the two pairs of hydrogen bonds that form critical interactions between the flap regions of the PR and the inhibitor. However, the $12 X$ FIV PR complex lacks the water molecule which bridges the P4 carboxybenzyl group and Asp3429 in the HIV PR-TL-3 complex [26]. 


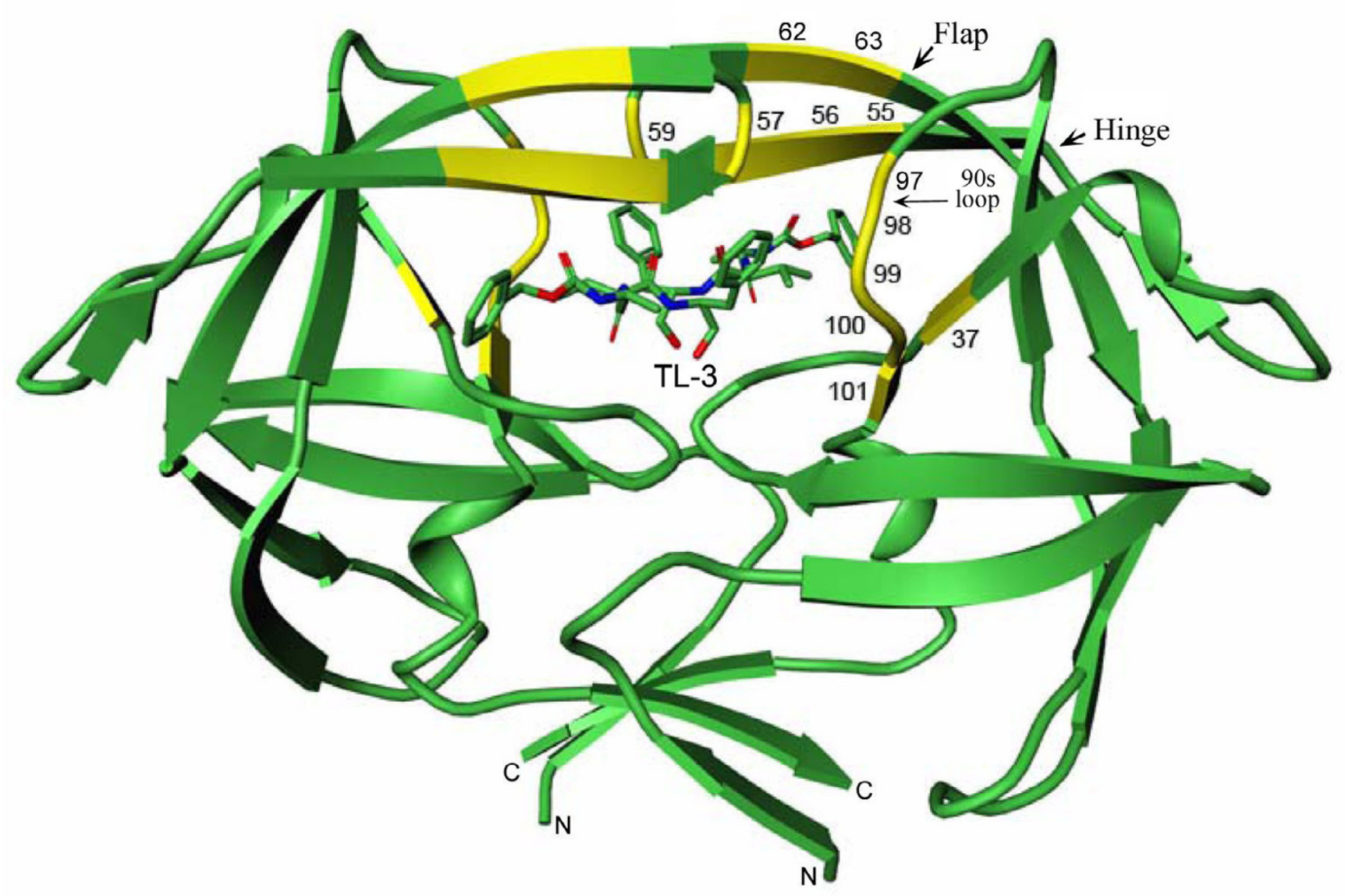

Figure I

Positions of mutation in chimeric I2X FIV protease. The residues that were mutated to generate the $12 \mathrm{X}$ mutant of FIV protease are indicated in yellow. These included I37V in the active site core, N55M, M56I, I57G, V59I, G62F, and K63I in the flap region, and L97T, I98P, Q99V, PI00N, and LIOII in the "90s loop" region. The 2-fold axis of the I2X FIV protease dimer is vertical in the plane of the figure; the $C_{2}$ axis of the bound inhibitor, TL-3, coincides with this 2-fold. All figures were generated using MoViT version I.2.I (Pfizer, La Jolla, CA, USA).

\section{Mutations localized to 90 s loop result in the formation of packing contacts with bound TL-3}

In HIV PR, the P1' phenyl ring of TL-3 is tightly packed against the side chains of Pro81 and Val82 in the "80s" loop of the two-fold related monomer [26]. In FIV PR, the structurally equivalent region spans residues 97 to 101 and is thus referred to here as the "90s loop". In this context, residues Ile9881 and Gln9982, are positioned too far away to form van der Waals interactions with the P1' phenyl group of TL-3 (Fig. 3). Five residues in the 90s loop have been mutated to their corresponding HIV PR residues in the $12 \mathrm{X}$ FIV PR; these include Leu9780Thr, Ile9881Pro, Gln9982Val, Pro10083Asn and Leu10184Ile. In the 12X FIV PR complex with TL-3, the P1' phenyl group is again able to pack against the side chains of Pro $98^{81}$ and Val9982 reforming important interactions between the protein and inhibitor (Fig. 3). The ability of the 90s loop to shift towards the bound TL-3 and reform this packing contact is facilitated by three additional mutations, Ile3732 Val, Leu9780Thr and Leu10184Ile. In the WT FIV PR-TL-3 complex, the side chain of Ile $37^{32}$ forms packing contacts with the side chains of Leu9780 and Leu10184 which holds the 90s loop in position, away from the P1' subsite of TL-3 (Fig. 4). The mutation of Ile3732 to Val, Leu $97^{80}$ to Thr, and Leu10184 to Ile abolishes these packing contacts, allowing the 90s loop to shift toward the bound inhibitor, therefore promoting the reformation of the packing contacts between the P1' phenyl group of TL3, Pro9881 and Val9982. Hence, the "HIVinizing" replacements affect TL-3 binding directly, and indirectly, as a consequence of buried side chain interactions. Restoration of the packing interactions increases the inhibition by TL-3 relative to wild-type FIV PR by a factor of $3.7\left(\mathrm{~K}_{\mathrm{i}}{ }^{12 \mathrm{X}}\right.$ FIV PR = $10 \mathrm{nM} ; \mathrm{K}_{\mathrm{i}}$ WT FIV PR $=41 \mathrm{nM}$ ) [2-4]. However, TL-3 


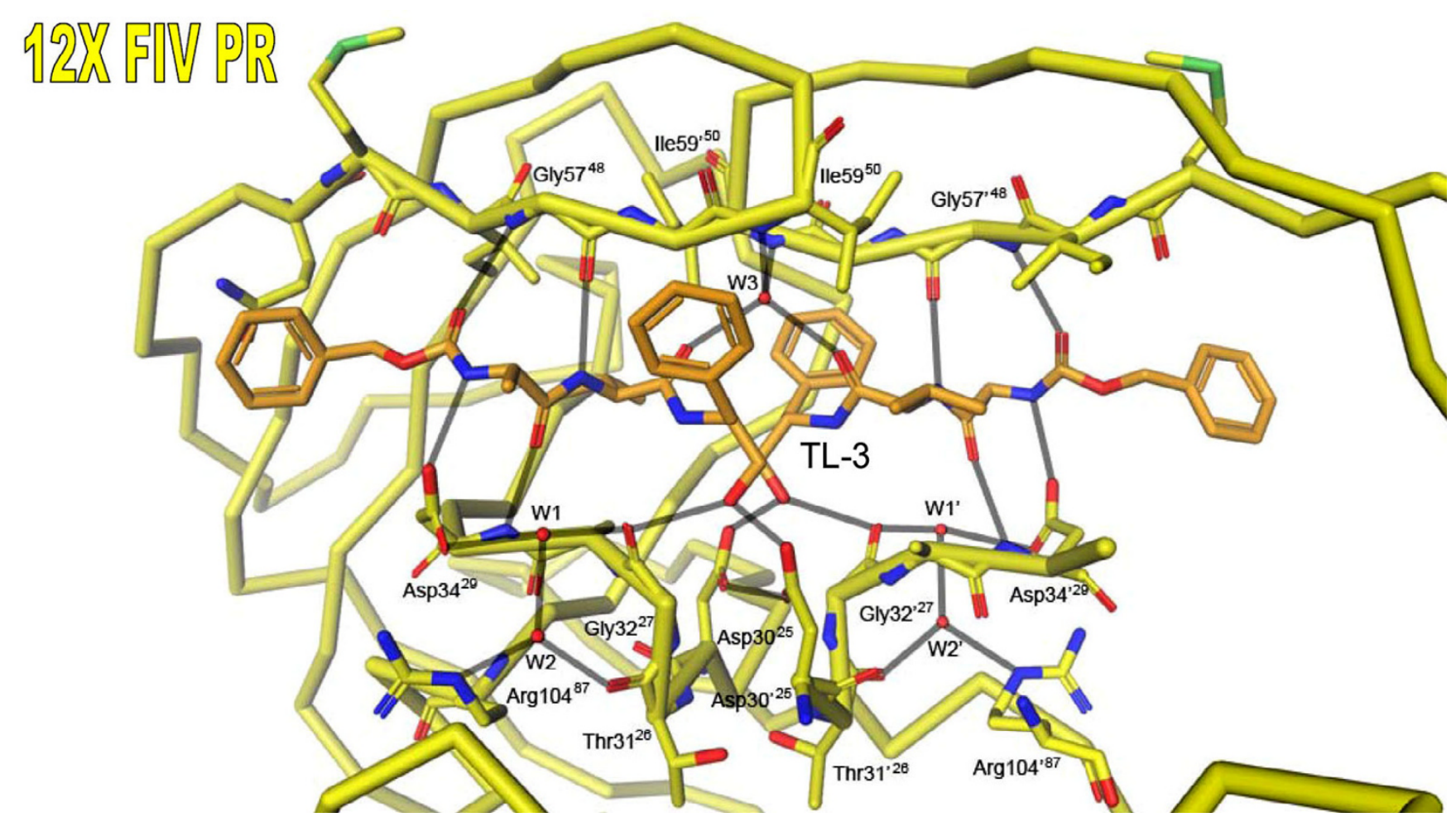

Figure 2

Conformation of I2X FIV protease in complex with the inhibitor TL-3. The hydrogen bonding network between TL3 and I2X FIV protease is formed predominantly by main chain atoms of residues in the catalytic loop (residues 30-34) and flap regions (residues G57, I59) of the protease. The network is mediated by five ordered water molecules (WI-W3, WI'-W2'). This hydrogen bonding network is essentially identical to that formed by TL-3 in the active sites of both wild-type HIV and FIV protease [II, 12, I3, 26]. The equivalent residue numbers for HIV protease are indicated in superscript.

inhibition remains over 7 -fold weaker relative to wildtype HIV PR $\left(\mathrm{K}_{\mathrm{i}}^{\mathrm{HIV} P R}=1.5 \mathrm{nM}\right)$.

\section{Intra-flap and inter-flap interactions stabilize the closed conformation of the flap regions in I2X FIV PR}

Six of the mutations introduced into $12 X$ FIV PR are localized to the flap regions of the protein; Asn $55^{46} \mathrm{Met}$, Met5647Ile, Ile5748 Gly, Val5950Ile, Gly6253Phe, Lys6354Ile (Fig. 1). Residues 55, 62 and 63 are positioned in the center of the flaps with their side chains pointing away from the active site (Fig. 5(a), (b)). The mutation of Asn $55^{46}$ to Met and Gly62 $2^{53}$ to Phe in 12 X FIV PR results in the formation of two intra-flap interactions: a packing contact formed between the $\mathrm{C}^{\varepsilon}$ atom of Met $55^{46}$ and the side chain of Phe6253, and an electrostatic interaction between the $S^{\delta}$ atom of Met5546 and the $\mathrm{N}^{\varepsilon}$ atom of Arg6455 (Fig. 5(b)). This pair of intra-flap interactions closely mimics the pair of intra-flap packing contacts between Met46, Phe53 and Lys55 seen in the HIV PR-TL3 complex structure (Fig. 5(c)) $[13,26]$. Additional mutations of Val5950 to Ile and Lys $63^{54}$ to Ile result in the formation of flap interactions between monomers that is not present in wild-type FIV PR (Fig. 1). The introduction of the intra-flap and inter-flap interactions in $12 \mathrm{X}$ FIV PR may help to stabilize the closed conformation of the flap regions, and may be a contributing factor to the increased inhibition by TL-3. The stabilization of the flaps could increase the thermodynamic barrier to flap opening and, therefore affect substrate processing efficiency by increasing the residence time of substrate in the active site.

\section{Discussion}

$12 \mathrm{X}$ FIV PR is a transitional mutant with engineered drug susceptibility. The mutations found in 12X FIV PR change residues from their native amino acids to those at structurally equivalent positions in HIV PR. In this way, $12 \mathrm{X}$ FIV PR can be considered a transitional mutant that exhibits intermediate susceptibility to TL-3 $\left(\mathrm{K}_{\mathrm{i}}\right.$ WT FIV PR $=41 \mathrm{nM}$; $\mathrm{K}_{\mathrm{i}}^{12 X}$ FIV PR $=10 \mathrm{nM} ; \mathrm{K}_{\mathrm{i}}^{\mathrm{HIV} P R}=1.5 \mathrm{nM}$ ). While the $12 \mathrm{sub}$ stitutions have no affect on the hydrogen bonding pattern between the protein and inhibitor, they do affect the packing interactions. The 90s loop in 12X FIV PR more closely resembles the 80 s loop of HIV PR in sequence and conformational flexibility. The removal of a packing contacts formed by Val3732, Thr9780 and Ile10184 allows the 90s loop to shift more closely to the bound inhibitor. With 


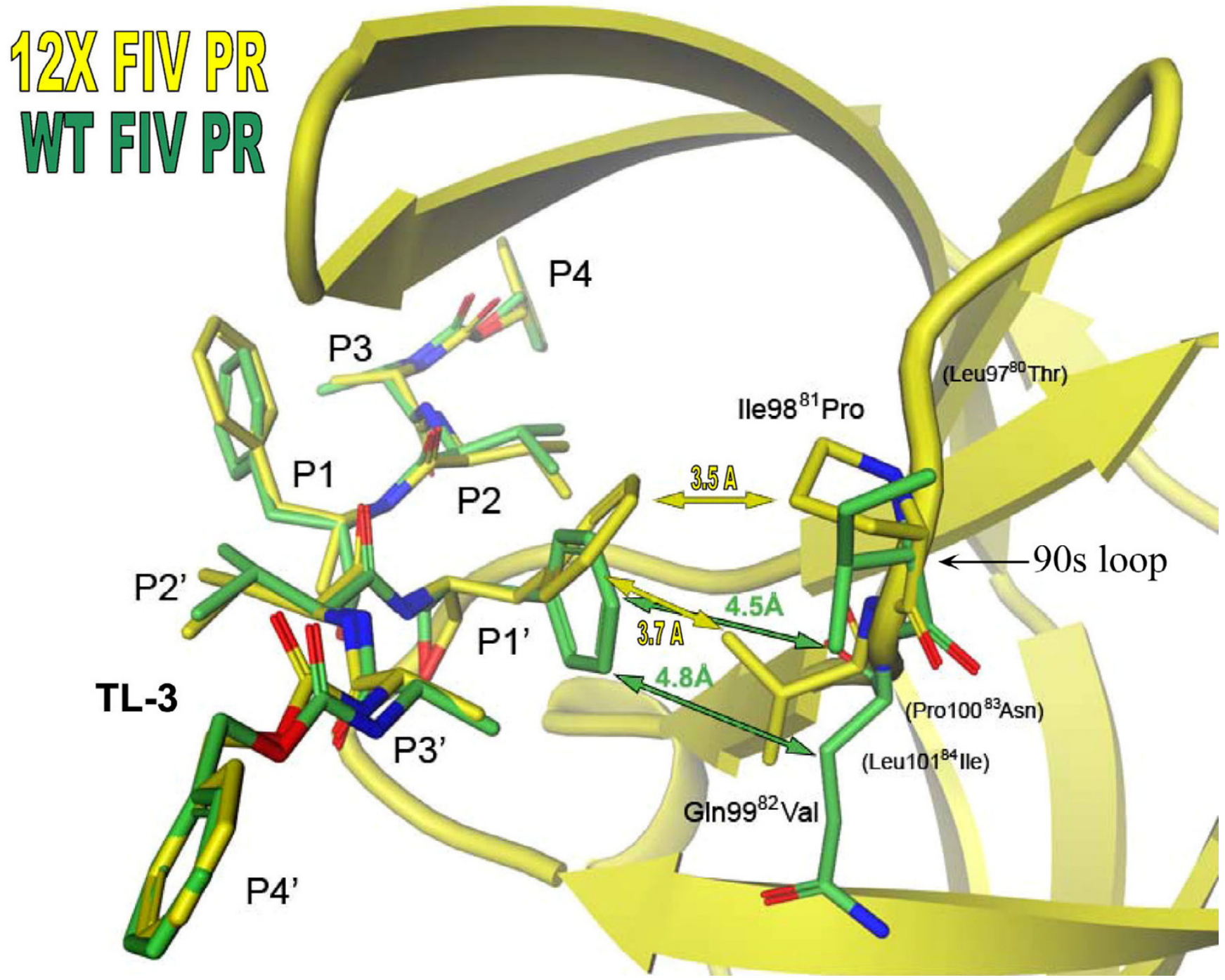

Figure 3

Effects of the 90s loop mutations on interactions with TL-3. Comparisons of the TL-3 complexes of wild-type FIV protease (green) and I2X protease (yellow) reveals conformational differences at the PI/PI' position of the inhibitor. The mutation of residue 98 from Isoleucine to Proline and residue 99 from Glutamine to Valine in the I2X mutant protease allows the formation of packing contacts with the PI/PI' position of TL-3, causing the PI/PI' phenyl ring to shift toward the side chain of Proline 98 by $2.0 \AA$ and rotate by $21^{\circ}$ about the $\chi^{\prime}$ torsion angle. These movements are facilitated by other mutations in the $90 \mathrm{~s}$ loop and active site core (see Fig. 4).

the additional mutations of Ile98 81 to Pro and Gln9982 to Val, the 90s loop becomes able to form the packing interaction with the P1' phenyl group of TL-3 as seen in the complex between HIV PR and TL-3. The loss of this particular packing contact was previously reported to result in a nearly 4-fold decrease in inhibition by TL-3 in 1 X HIV PR, where $1 \mathrm{X}$ represents the V82A mutant $\left(\mathrm{IC}_{50}\right.$ WTHIVPR $=6$ $\mathrm{nM} ; \mathrm{IC}_{50} 1 \mathrm{X}$ HIV PR $\left.=22 \mathrm{nM}\right)[1,26]$. Hence, it is reasonable that recovery of this interaction in the $12 \mathrm{X}$ FIV PR would have the opposite affect, contributing to the TL-3 suscep- tibility of the enzyme $\left(\mathrm{IC}_{50}\right.$ WT FIV PR $=90 \mathrm{nM} ; \mathrm{IC}_{50} 12 \mathrm{X}$ FIV PR $=71 \mathrm{nM}$ ).

The above findings account for observed changes in inhibitor specificity in the HIV/FIV chimeric PRs and support the involvement of targeted residues in the hinge, flap, and 90s loop in inhibitor binding (Fig. 1). Interestingly, changes in substrate cleavage are harder to institute, so that the virus is able to develop inhibitor resistance while replicating sufficiently to maintain virus production. As many as 24 HIV amino acid substitutions have been made 


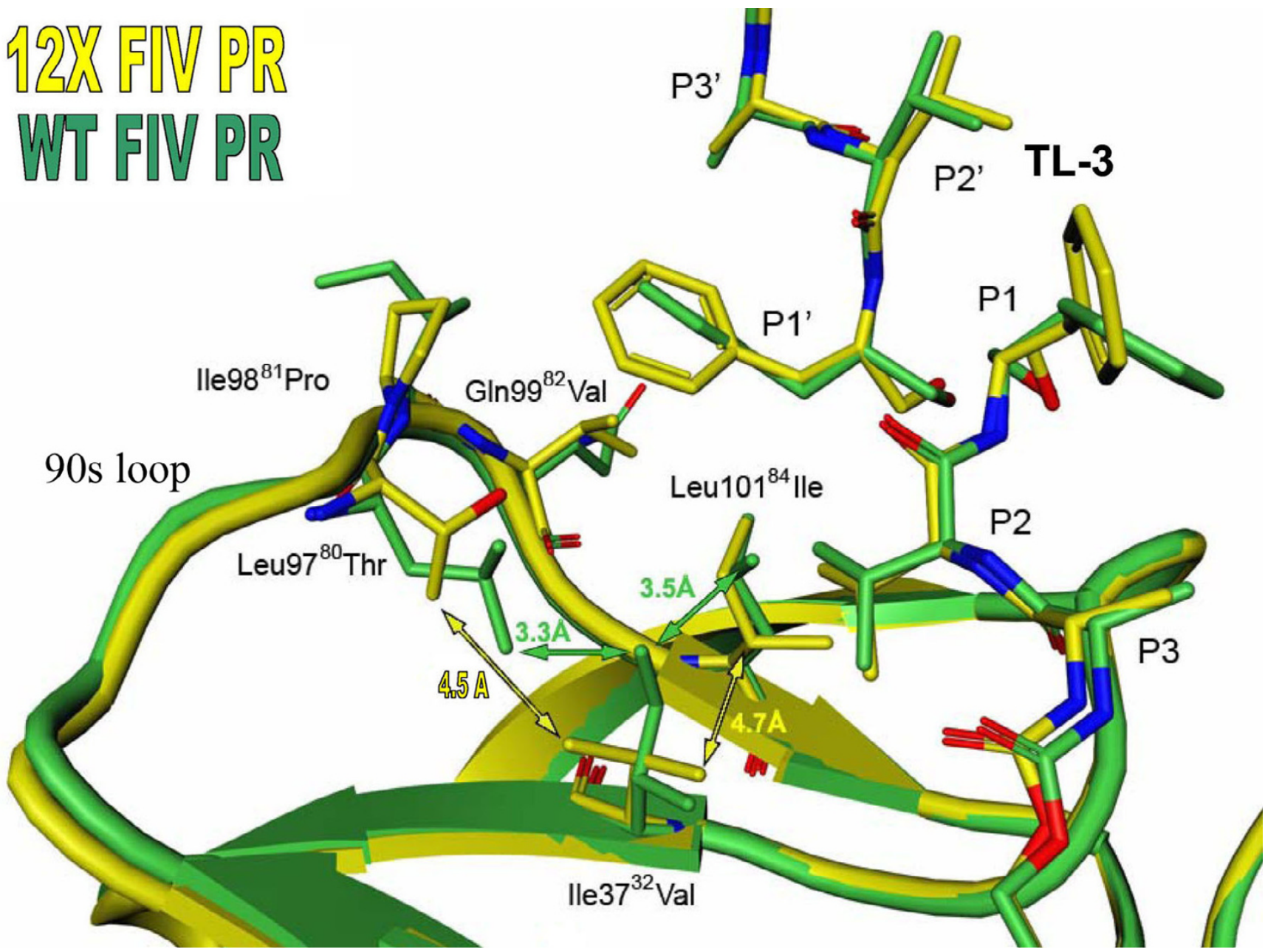

Figure 4

Changes in the packing contacts between the active site core and 90 s loop. The reformation of the PI/PI' interaction of TL-3 and the 90s loop is aided by the loss of packing interactions between residue 37 in the active site and the 90s loop. In wild-type FIV protease (green) the side chain of Isoleucine 37 forms packing contacts with the side chains of Leucine 97 and Leucine 10I, holding the 90s loop in position away from TL-3. The mutation of Isoleucine 37 to Valine, Leucine 97 to Threonine, and Leucine $\mathrm{IOI}$ to Isoleucine in the I2X mutant protease (yellow) eliminates these packing contacts, allowing the 90s loop to shift $\sim$ I.0 $\AA$ toward the PI/PI' position of TL-3.

in the FIV PR background without substantially increasing HIV substrate cleavage [17]. Mutations that increase stability in the flap allow a degree of cleavage of HIV substrates by FIV, but levels do not approach that obtained by HIV PR [17]. Several of the mutations in the 12X FIV PR could affect the stability of the flaps in either the open or closed state. In addition to Met5 $55^{46}$ and Phe $62^{53}$, which stabilize individual flaps (Fig. 5b), Ile5950 and Ile6354 could form reciprocal packing interactions between flaps, favoring a closed conformation [27]. Loss of an equivalent interaction results in a $6 \AA$ separation between flaps in the Phe53Leu mutant of apo-HIV PR [28]. Two of the flap residues replaced in $12 \mathrm{X}$ FIV PR (Asn5546 Met, Lys6354Ile) are also sites of mutation in the 'wide-open' conformation of a multidrug-resistant HIV PR [29]. Molecular dynamics studies suggest that hydrophobic clustering of Val3732, Ile5950, Pro98 $8^{81}$, and Val99 ${ }^{82}$ within monomers could stabilize an open conformation of the enzyme [27]. Saturation mutagenesis of HIV PR shows that of six flap residues mutated in 12X FIV PR, four (Met $55^{46}$, Gly5748, Ile5950, and Phe6253) result in intermediate activity if inserted into HIV PR, and two (Ile56 ${ }^{47}$ and Ile6354) inactivate the enzyme [30]. Clearly, the overall character of the PR contributes to the observed substrate specificity with the conformational preferences of the flaps being critical. 

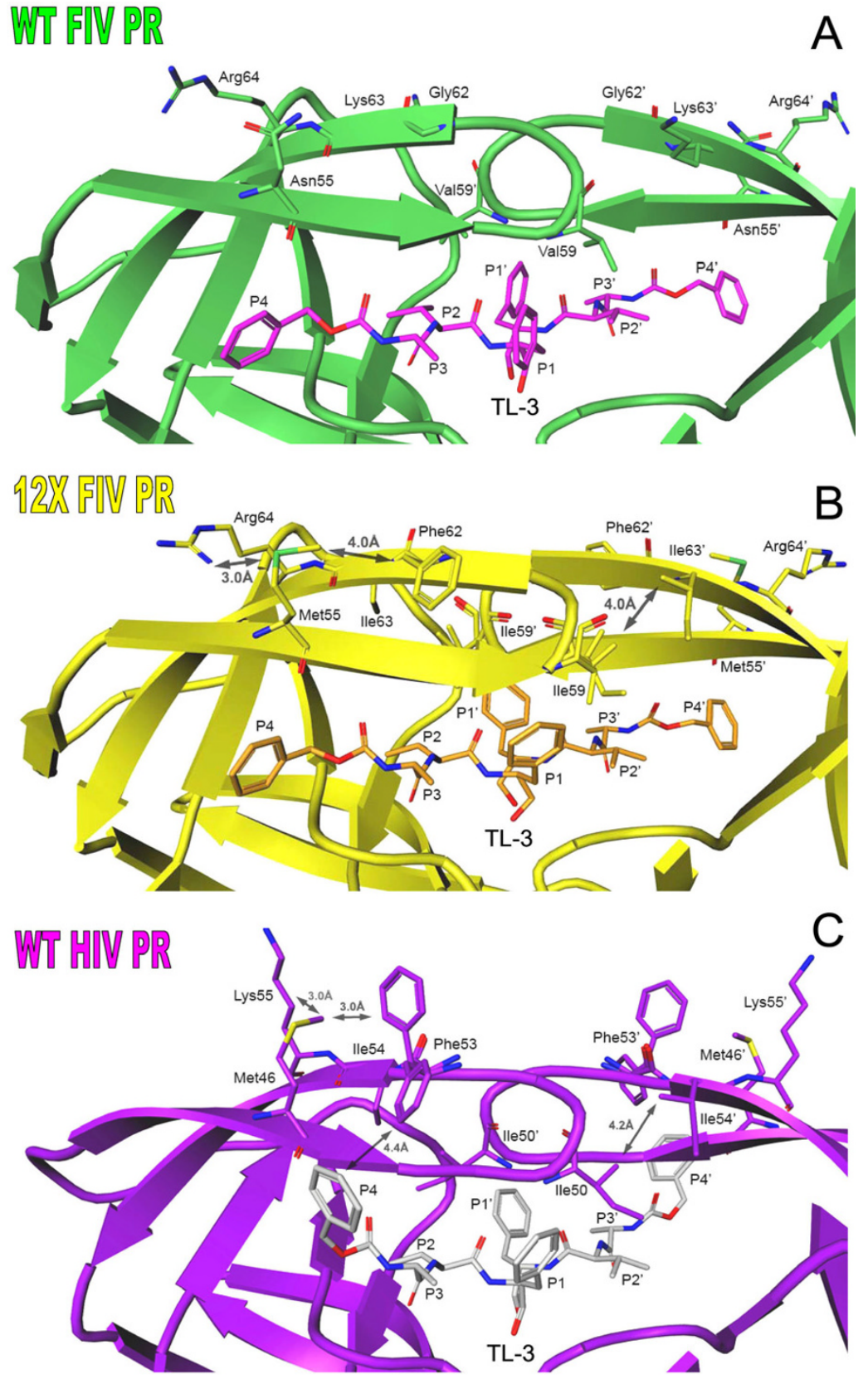

\section{Figure 5}

Comparison of the flap regions of wild-type FIV protease, I2X FIV protease, and wild-type HIV protease. (a) In the wild-type FIV protease, residues positioned at the top and tips of the flaps are not able to form stabilizing interactions. (b) In the 12X mutant Asparagine 55 has been mutated to Methionine and Glycine 62 has been mutated to Phenylalanine, allowing the formation of an intra-flap packing contact between these two residues and an electrostatic interaction between $\mathrm{S}^{\delta}$ of Methionine 55 and $\mathrm{N} \eta$ of Arginine 64. Two additional substitutions in the flap regions of I $2 X$ FIV protease, Valine 59 to Isoleucine, and Lysine 63 to Isoleucine, result in the formation of an inter-flap packing contact between the isoleucines (Isoleucine 59 ... Isoleucine 63'). The introduction of stabilizing contacts due to these mutations increases the overall stability of the closed conformation of the flaps. (c) The stabilizing contacts formed as a result of the I $2 \mathrm{X}$ flap mutations closely resemble those seen in the structure of wild-type HIV in complex with TL-3. The side chain of Methionine 46 is packed between the side chains of Phenylalanine 53 and Lysine 55 in the wild-type HIV protease, just as Methionine 55 is packed between the side chains of Phenylalanine 62 and Arginine 64 in I2X FIV protease (b). Also as in I2X FIV protease, an inter-flap packing contact is formed in HIV protease between Isoleucine 50 and Isoleucine 54'. 
In addition, the context of PR in the natural substrate has a direct impact on overall processing efficiency. The critical role for PR in the virus life cycle is not only to process the Gag and Gag-Pol proteins specifically [31,32], but also to perform cleavages in the proper order and temporal sequence [33]. The processing sequence and efficiency of the HIV-1 Gag-Pol polyprotein has been studied in great detail and has been shown to be critical to generate infectious virus $[20,33,34]$. Of note is the finding that proper temporal cleavage of the Gag-Pol polyprotein is influenced by conformational constraints on PR "embedded" in the context of the polyprotein such that minor amino acid changes can alter the order of polyprotein cleavage [35]. In particular, the replacement $\mathrm{P} 1 \mathrm{~A}$ appears to enhance mobility of the dimeric, embedded protease $[21,35]$. Recent studies of FIV using the 12X mutant and additional FIV/HIV PR chimeras, when placed in the context of the Gag and Gag-Pol polyprotein, are consistent with the findings in HIV PR [4]. The results show that the chimeric PRs cleave the natural Gag polyprotein substrate expressed in the context of pseudovirions. However, the addition of HIV residues with concomitant increase in HIV character results in inappropriate order of cleavage [4]. Specifically, the NC-p2 cleavage junction was processed efficiently by wild type FIV PR, but poorly by the "HIVinized" FIV mutants. The junctions on either side of $\mathrm{NC}$ are the earliest processing sites and the proper timing of these cleavages is critical to generation of infectious HIV virions [20,21,34]. FIVs encoding the chimeric PRs are non-infectious and it is probable that temporal changes in processing are responsible, due to altered rates of cleavage arising from the structural changes identified here. Increased rigidity of the flaps of HIV PR has been previously demonstrated to alter substrate cleavage kinetics by increasing the off-rate [36]. Recent molecular dynamics simulations have emphasized the importance of flap mobility on function in the crowded molecular environment of the cell [37]. The phenomenon has also been observed in other systems where allosteric effects have led to an increased residency time in the enzyme active site $[38,39]$. Obtaining the structure of $\mathrm{PR}$ in the context of the polyprotein would be of great interest in better defining structural constraints, and stands as a challenge for future experimentation.

\section{Conclusion}

The 1.7 Å resolution crystal structure of FIV protease (PR), in which 12 critical residues around the active site have been substituted with structurally equivalent residues in HIV PR, was determined in complex with the broad-based inhibitor TL-3. The structure, in comparison with structures of HIV and FIV PRs with TL-3 bound, demonstrates how substitutions which make FIV PR more HIV-like result in altered inhibition constants in the order HIV PR $>12$ X FIV PR > FIV PR. The analysis shows how 12X FIV
PR gains several stabilizing intra- and inter-flap interactions that resemble those in HIV PR, while retaining hydrogen bonding interactions common to both FIV and HIV PRs. The structural details suggest that changes in flap mobility may be related to changes in substrate processing efficiency, thereby affecting cleavage of Gag and Gag-Pol sites by FIV vs. HIV protease. The results provide better understanding of the molecular basis of HIV-1 and FIV protease (PR) substrate specificities in vivo, and are relevant to the development of broad-spectrum protease inhibitors that can inhibit both wild type and drug-resistant proteases.

\section{Methods \\ Mutagenesis of chimeric FIV PRs}

Chimeric FIV PRs were constructed by substituting the residues of FIV PR for the structurally equivalent residues of HIV-1 PR with PCR-mediated megaprimer site-directed mutagenesis as described [17]. The chimeric PR genes were digested with NdeI and HindIII and cloned into pET21a (Novagen, Inc.). The substitutions were verified by dideoxy DNA sequencing. All protease constructs were over-expressed in E. coli strain BL21.DE3/pLysS using T7driven expression in the context of the pET21 vector (Novagen) [13,17]. Expression was induced by treatment of late log phase cells with $1 \mathrm{mM}$ isopropylthiogalactopyranoside (IPTG) for $3 \mathrm{hr}$ at $37^{\circ} \mathrm{C}$.

\section{Purification and refolding of mutant FIV PR}

PRs were purified and re-folded for crystallization following the previously described procedure [2]. Inclusion bodies containing $12 \mathrm{X}$ protease were purified by resuspending the cell pellet from 1 liter of cell culture in $20 \mathrm{mM}$ Tris, 2 mM EDTA (TE), pH 8 buffer containing 1\% NP-40 and stirring for $20 \mathrm{~min}$ at RT. The solution was then treated in a Waring blender for 30 seconds, and $100 \mathrm{ml}$ of $8 \mathrm{M}$ urea + TE buffer was added with stirring at $4 \mathrm{deg} C$ for $20 \mathrm{~min}$. Inclusion bodies were pelleted at $8,000 \times \mathrm{g}$ for $1 \mathrm{hr}$. and subsequently washed with deionized water until the pelleted inclusion bodies stuck to the side of the centrifuge tube (typically after the third wash). Inclusion bodies were solubilized in $8 \mathrm{M}$ urea in TE buffer, $10 \mathrm{mM}$ DTT with gentle rocking overnight at $4^{\circ} \mathrm{C}$. Insoluble material was removed by centrifugation, followed by filtration through a $0.45 \mu \mathrm{m}$ membrane. Solid DE52 (Whatman; 20 g) was then added and the solution was incubated at $4{ }^{\circ} \mathrm{C}$ for $1 \mathrm{hr}$. and then filtered through a $0.45 \mu \mathrm{m}$ membrane. The DE52 was discarded and the filtered solution containing protease was then applied to an RQ column (J.T. Baker) that had been equilibrated in $8 \mathrm{M}$ urea, $20 \mathrm{mM}$ Tris, 2 mM EDTA, pH 8.0. The column flow through containing the protease was collected and refolded by dialysis against $20 \mathrm{mM}$ sodium phosphate, $\mathrm{pH} 7.2,25 \mathrm{mM} \mathrm{NaCl}$, and $0.2 \%$ 2-mercaptoethanol overnight at $4{ }^{\circ} \mathrm{C}$, followed by dialysis against $10 \mathrm{mM}$ sodium acetate, $\mathrm{pH} 5.2,0.2 \%$ 
2-mercaptoethanol for $3 \mathrm{hr}$. The refolded protease was centrifuged for $20 \mathrm{~min}$. at $38,000 \mathrm{~g}$ at $4^{\circ} \mathrm{C}$ to remove any precipitated material. The sample was then concentrated using a centrifuge concentrator (Amicon Ultra 10,000 MW cut-off), washed twice with $20 \mathrm{mM}$ sodium acetate, pH 5.2 saturated with TL-3, and then concentrated to 5$10 \mathrm{mg} / \mathrm{ml}$.

\section{Crystallization and data collection Crystallization}

$1 \mu \mathrm{l}$ of $12 \mathrm{X}$ FIV PR at $2.5 \mathrm{mg} / \mathrm{ml}$ with added TL-3 was mixed with $1 \mu$ of $2.5 \mathrm{M}$ lithium chloride, $100 \mathrm{mM}$ Hepes, pH 7.5, and equilibrated by hanging drop vapor diffusion against this reservoir solution at $8^{\circ} \mathrm{C}$. Prismatic trigonal crystals formed within one week. The crystals were transferred to a synthetic mother liquor solution containing $15 \%$ propylene glycol for a several seconds, and then flash frozen in liquid $\mathrm{N}_{2}$.

\section{Data collection}

Diffraction data were collected at $100 \mathrm{~K}$ by the rotation method (120 frames, $1^{\circ}$ oscillation per frame) to $1.7 \AA$ resolution at beam line $1-5(\lambda=0.979 \AA)$ at the Stanford Synchrotron Radiation Laboratory. The data were processed with Mosflm [40] and Scala [41] (Table 1).

\section{Structure solution and refinement}

The structure of $12 \mathrm{X}$ FIV protease was solved by molecular replacement at $3 \AA$ resolution using coordinates of the monomer of wild-type FIV protease (PDB 1B11) as a

Table I: Crystallographic Statistics

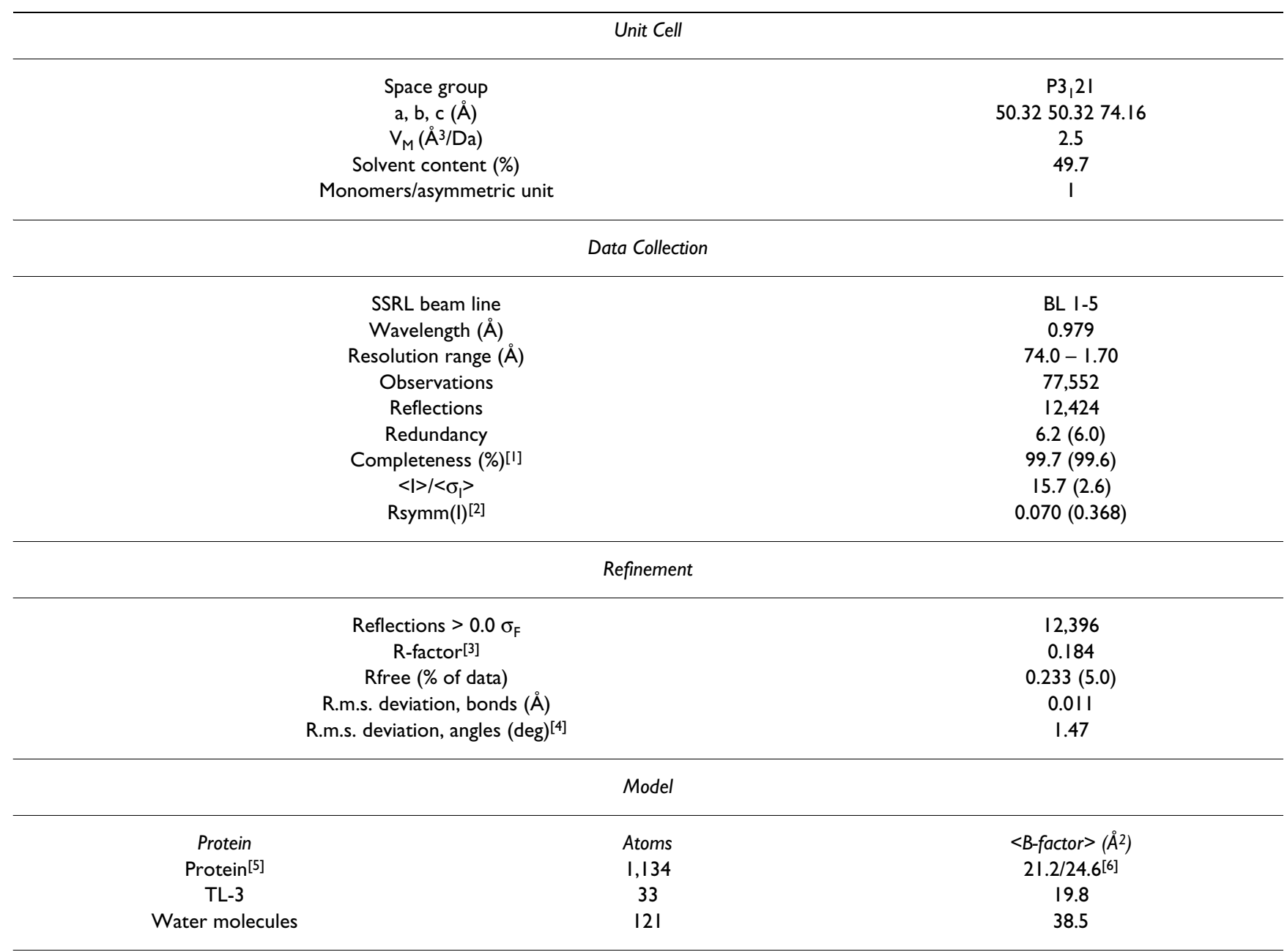

[I] Values for highest resolution shell in parentheses.

[2] $\mathrm{R}_{\text {symm }}=\Sigma_{\mathrm{hkl}} \Sigma_{\mathrm{i}} \mathrm{l}_{\mathrm{i}}(\mathrm{hkl})-\mathrm{l}(\mathrm{hkl}) \mid / \Sigma_{\mathrm{hkl}} \Sigma_{\mathrm{i}}(\mathrm{l}(\mathrm{hkl}))$ where $\mathrm{l}_{\mathrm{i}}(\mathrm{hkl})$ is the intensity of an individual measurement, and $\mathrm{l}(\mathrm{hkl})$ is the mean intensity of this reflection.

[3] R-factor $=\Sigma_{\text {hkl }}\left|F_{\text {obs }}\right|-\left|F_{\text {calc }}\right| / \Sigma_{\text {hk }}\left|F_{\text {obs }}\right|$, where $\left|F_{\text {obs }}\right|$ and $\left|F_{\text {calc }}\right|$ are observed and calculated structure factor amplitudes, respectively.

[4] Ramachandran plot: $95.9 \%$ of residues in most favored regions; $3.1 \%$ in allowed regions, $1.0 \%$ in disfavored regions.

[5] Includes residues with alternate conformations.

[6] Average B-factors for main chain and side atoms, respectively. 
search model in Molrep [42]. Residues differing in sequence between the two proteins were modeled as alanines. Five percent of randomly selected reflections were designated as test reflections for use in the Free- $\mathrm{R}$ cross-validation method [43] and used throughout the refinement. The correlation coefficient and R-factor from the molecular replacement solutions indicated that the correct space group was $P 3_{1} 21$. Rigid body and restrained refinement were performed in Refmac [44] at $3 \AA$ and 2.0 $\AA$, respectively. Simulated annealing, Powell minimization and individual temperature factor refinements were performed using CNS [45]. After refinement, the model was adjusted and correct amino acids were built into regions of the composite omit map using the visualization program O [46]. The model was refined in CNS [45] using a bulk solvent correction and isotropic B-factors, followed by several rounds of model adjustment using the SigmaAweighted $2\left|\mathrm{~F}_{\mathrm{o}}\right|-\left|\mathrm{F}_{\mathrm{c}}\right|$ and $\left|\mathrm{F}_{\mathrm{o}}\right|-\left|\mathrm{F}_{\mathrm{c}}\right|$ electron density maps [47] generated in CNS [45]. TL-3 was initially modeled by superposition of the wild-type FIV structure in complex with TL-3 (1B11). The conformation of the bound TL-3 was manually adjusted to fit the SigmaA-weighted $\left|\mathrm{F}_{\mathrm{o}}\right|$ -

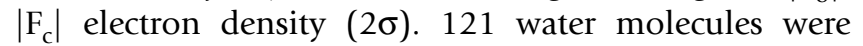
added and nine residues were model as having alternate side chain conformations. The region between Ile59 and Gly61 was modeled with two main chain conformations that contained a flipped peptide bond between Ile59 and Gly60. The model was refined to a final $\mathrm{R}_{\text {cryst }} / \mathrm{R}_{\text {free }}$ of $18.4 /$ 23.3\% [43,45] (Table 1).

\section{Protein Data Bank accession numbers}

The 12X FIV protease complex crystal structure with the inhibitor TL-3 has been deposited into the RCSB Protein Data Bank and has been assigned the accession code 2HAH.

\section{Competing interests}

The author(s) declare that they have no competing interests.

\section{Authors' contributions}

YCL and KT prepared the protein samples, and HH grew the crystals and performed crystallographic analysis. BET and JHE developed the TL-3 inhibitor, and JHE directed the design of the $12 \mathrm{X}$ chimeric FIV protease. CDS supervised the structural analysis. All authors read and approved the final manuscript.

\section{Acknowledgements}

C.D. Stout, B.E. Torbett and J.H. Elder are supported by the N.I.H. grant GM48870. Additional support for B.E. Torbett and J.H. Elder comes from the N.I.H. grant Al40882. We would like to thank Duncan McRee, Isaac Hoffman, Robin Rosenfeld and the staff at Active Sight, San Diego, for assistance in crystallization screening. We thank the staff of the Stanford Synchrotron Radiation Laboratory (SSRL) for expert technical support and access to resources. SSRL is a national user facility operated by Stanford
University on behalf of the U.S. Department of Energy, Office of Basic Energy Sciences. The SSRL Structural Molecular Biology Program is supported by the Department of Energy, Office of Biological and Environmental Research, and by the National Institutes of Health, National Center for Research Resources, Biomedical Technology Program, and the National Institute of General Medical Sciences.

\section{References}

I. Buhler B, Lin YC, Morris G, Olson AJ, Wong C-H, Richman DD, Elder $\mathrm{J}$, Torbett BE: "Viral evolution in response to the broadbased retroviral protease inhibitor TL-3". J Virol 200I, 75:9502-9508.

2. Lee T, Laco GS, Torbett BE, Fox HS, Lerner DL, Elder JH, Wong C$\mathrm{H}$ : "Analysis of the $S 3$ and $S 3$ ' subsite specificities of feline immunodeficiency virus (FIV) protease: Development of a broad-based protease inhibitor efficacious against FIV, SIV, and HIV in vitro and ex vivo". Proc Natl Acad Sci USA 1998, 95:939-944.

3. Lee T, Le V-D, Lim D, Lin Y-C, Wong AL, Morris GM, Olson AJ, Elder $\mathrm{J}$, Wong $\mathrm{C}-\mathrm{H}$ : "Development of a new type of protease inhibitors, efficacious against FIV and HIV variants". I Am Chem Soc 1999, I 2 1: | | 45-| I55.

4. Lin Y-C, Brik A, Parseval AD, Tam K, Torbett BE, Wong C-H, Elder $\mathrm{JH}$ : "Altered Gag Polyprotein Cleavage Specificity of FIV/HIV Mutant Proteases as Demonstrated in a Cell-Based Expression System". J Virol 2006, 80:7832-7843.

5. Elder $\mathrm{JH}$, Phillips TR: "Feline immunodeficiency virus as a model for development of molecular approaches to intervention strategies against lentivirus infections". Adv Virus Res 1995, 45:225-247.

6. Henriksen SJ, Prospero-Garcia O, Phillips TR, Fox HS, Bloom FE, Elder JH: "Feline immunodeficiency virus as a model for study of lentivirus infection of the central nervous system". Curr Top Microbiol Immunol 1995, 202:167-186.

7. Elder JH, Dean GA, Hoover EA, Hoxie JA, Malim MH, Mathes L, Neil JC, North TW, Sparger E, Tompkins MB, Tompkins WAF, Yamamoto J, Yuhki N, Pedersen NC, Miller RH: "Lessons from the cat: feline immunodeficiency virus as a tool to develop intervention strategies against human immunodeficiency virus type I". AIDS Res Hum Retroviruses 1998, 14:797-80I.

8. Le VD, Mak CC, Lin Y-C, Elder JH, Wong C-H: "Structure-activity studies of FIV and HIV protease inhibitors containing allophenylnorstatine". Bioorg Med Chem 200I, 9:। I85-II95.

9. Mak CC, Le V-D, Lin Y-C, Elder JH, Wong C-H: "Design, synthesis, and biological evaluation of HIV/FIV protease inhibitors incorporating a conformationally constrained macrocycle with a small P3' residue". Bioorg Med Chem Lett 200 I, I I:21 9-222.

10. CC Mak, Brik A, Lerner DL, Elder JH, Morris GM, Olson AJ, Wong $\mathrm{C}-\mathrm{H}$ : "Design and synthesis of broad-based mono- and bicyclic inhibitors of FIV and HIV proteases". Bioorg Med Chem 2003, I I:2025-2040.

II. Wlodawer A, Gustchina A, Reshetnikova L, Lubkowski J, Zdanov A, Hui KY, Gngleton EL, Farmerie WG, Goodenow MM, Bhatt D, Zhang L, Dunn BM: "Structure of an inhibitor complex of the proteinase from feline immunodeficiency virus". Nat Struct Biol 1995, 2:480-488.

12. GS Laco, Schalk-Hihi C, Lubkowski J, Morris G, Zdanov A, Olson A, Elder JH, Wlodawer A, Gustchina A: "Crystal structures of the inactive D30N mutant of feline immunodeficiency virus protease complexed with a substrate and an inhibitor". Biochem 1997, 36:10696-10708.

13. Li M, Morris GM, Lee T, Laco GS, Wong C-H, Olson AJ, Elder JH, Wlodawer A, Gustchina A: "Structural studies of FIV and HIVI protease complexed with an efficient inhibitor of FIV protease". Proteins: Struct Funct Gen 2000, 38:29-40.

14. Schnolzer M, Rackwitz H-R, Gustchina A, Laco GS, Wlodawer A, Elder JH, Kent SBH: "Comparative properties of feline immunodeficiency virus (FIV) and human immunodeficiency virus type I (HIV-I) proteinases prepared by total chemical synthesis". Virology 1996, 224:268-275.

15. Lin YC, Beck Z, Lee T, Le V-D, Morris GM, Olson AJ, Wong C-H, Elder JH: "Alteration of substrate and inhibitor specificity of feline immunodeficiency virus protease". J Virol 2000, 74:4710-4720. 
16. Beck ZQ, Lin YC, Elder JH: "Molecular basis for the relative substrate specificity of human immunodeficiency virus type I and feline immunodeficiency virus proteases". J Virol 200I, 75:9458-9469.

17. Lin Y-C, Beck Z, Morris GM, Olson AJ, Elder JH: "Structural basis for distinctions between substrate and inhibitor specificities for feline immunodeficiency virus and human immunodeficiency virus proteases". J Virol 2003, 77:6589-6600.

18. Elder JH, Schnolzer M, Hasselkus-Light CS, Henson M, Lerner DA Phillips TR, Wagaman PC, Kent SB: "Identification of proteolytic processing sites within the Gag and Pol polyproteins of feline immunodeficiency virus". J Virol 1993, 67:1869-| 876.

19. Swanstrom R, Wills J: Synthesis, assembly, and processing of viral proteins. In Retroviruses Edited by: Coffin J, Hughes S. NY, Cold Spring Harbor Laboratory Press; 1997:263-334.

20. Pettit SC, Sheng N, Tritch R, Erickson-Viitanen S, Swanstrom R: "The regulation of sequential processing of HIV-I Gag by the viral protease". Adv Exp Med Biol 1998, 436:15-25.

21. Pettit SC, Clemente JC, Jeung JA, Dunn BM, Kaplan AH: "Ordered Processing of the Human Immunodeficiency Virus Type I GagPol Precursor Is Influenced by the Context of the Embedded Viral Protease". J Virol 2005, 79:1060I-10607.

22. Swanstrom R, Erona J: "Human immunodeficiency virus typeprotease inhibitors: therapeutic successes and failures, suppression and resistance". Pharmacol Ther 2000, 86: I 45-70.

23. Beck ZQ, Morris GM, Elder JH: "Defining HIV-I protease substrate selectivity". Curr Drug Targets: Infect Disord 2002, 2:37-50.

24. Kutilek VD, Sheeter DA, Elder JH, Torbett BE: "Is resistance futile?". Curr Drug Targets: Infect Disord 2003, 3:295-309.

25. Kozal M: "Cross-resistance patterns among HIV protease inhibitors". AIDS Patient Care STDS 2004, I 8:199-208.

26. Heaslet H, Kutilek V, Morris GM, Lin Y-C, Elder JH, Torbett BE, Stout $\mathrm{CD}$ : "Structural insights into the mechanisms of drug resistance in HIV-I protease NL4-3". I Mol Biol 2006, 356:967-98I.

27. Tóth $G$, Borics A: "Flap opening mechanism of HIV-I protease". J Mol Graphics Model 2006, 24:465-474.

28. Liu F, Kovalevsky AY, Louis JM, Boross PI, Wang Y-F, Harrison RW, Weber IT: "Mechanism of Drug Resistance Revealed by the Crystal Structure of the Unliganded HIV-I Protease with F53L Mutation". I Mol Biol 2006, 358: I I 91-I 199.

29. Martin P, Vickrey JF, Proteasa G, Jimenez YL, Wawrzak Z, Winters MA, Merigan TC, Kovari LC: " 'Wide-Open' I.3 A Structure of a Multidrug-Resistant HIV-I Protease as a Drug Target". Struc ture 2005, I 3: 1887-1895.

30. Shao W, Everitt L, Manchester M, Loeb DD, Hutchison CA III, Swanstrom R: "Sequence requirements of the HIV-I protease flap region determined by saturation mutagenesis and kinetic analysis of flap mutants". Proc Natl Acad Sci USA 1997, 94:2243-2248.

31. Prabu-Jeyabalan M, Nalivaika E, Schiffer CA: "Substrate Shape Determines Specificity of Recognition for HIV-I Protease: Analysis of Crystal Structures of Six Substrate Complexex". Structure 2002, 10:369-381.

32. Ozer N, Haliloglu T, Schiffer CA: "Substrate Specificity in HIV-I Protease by a Biased Sequence Search Method". Proteins: Struct Func Bioinfor 2006, 64:444-456.

33. Pettit SC, Lindquist JN, Kaplan AH, Swanstrom R: "Processing sites in the human immunodeficiency virus type I (HIV-I) GagPro-Pol precursor are cleaved by the viral protease at different rates". Retrovirology 2005, 2:66.

34. Pettit SC, Moody MD, Wehbie RS, Kaplan AH, Nantermet PV, Klein CA, Swanstrom R: "The p2 domain of human immunodeficiency virus type I Gag regulates sequential proteolytic processing and is required to produce fully infectious virions". J Virol 1994, 68:8017-8027.

35. Pettit SC, Everitt LE, Choudhury S, Dunn BM, Kaplan AH: "Initial Cleavage of the Human Immunodeficiency Virus Type I GagPol Precursor by Its Activated Protease Occurs by an Intramolecular Mechanism". J Virol 2004, 78:8477-8485.

36. Lin $Y$, Lin $X$, Hong $L$, Foundling $S$, Heinrikson RL, Thaisrivongs $S$, Leelamanit W, Raterman D, Shah M, Dunn BM, Tang J: "Effect of Point Mutations on the Kinetics and the Inhibition of Human Immunodeficiency Virus Type I Protease: Relationship to Drug Resistance". Biochem 1995, 34: | |43-I I52.
37. Minh DLD, Chang C, Trylska J, Tozzini V, McCammon JA: "The influence of Macromolecular Crowding on HIV-I Protease Internal Dynamics". J Amer Chem Soc 2006, I 28:6006-6007.

38. Lai C], Harris BG, Cook PF: "Mechanism of activation of the NAD-malic enzyme from Ascaris suum by fumarate". Arch Biochem Biophys 1992, 299:214-219.

39. Jeannin E, Robyr D, Desvergne B: "Transcriptional regulatory patterns of the myelin basic protein and malic enzyme genes by the thyroid hormone receptors alphal and betal". J Biol Chem 1998, 273:24239-24248.

40. Leslie AGW: The CCP4 Suite: Programs for Protein Crystallography. Acta Crystallogr 1992, D50:760-763.

4I. Kabsch W: "Evaluation of single-crystal X-ray diffraction data from a position sensitive detector". J of Appl Cryst 1988, 21:916-924.

42. Vagin A, Teplyakov A: "An approach to multi-copy search in molecular replacement". Acta Crystallogr 2000, D56:1622-1624.

43. Brünger AT: "The free $\mathbf{R}$ value: a novel statistical quantity for assessing the accuracy of crystal structures". Nature 1992, 355:472-474

44. Murshudov GN, Vagin AA, Dobson EJ: "Refinement of macromolecular structures by the maximum-likelihood method". Acta Crystallogr 1997, D53:240-255.

45. Brünger AT, Adams PD, Clore GM, DeLano WL, Gros P, GrosseKunstleve RW, Jiang J-S, Kuszewski J, Nilges M, Pannu NS, Read RJ, Rice LM, Simonson T, Warren GL: "Crystallography \& NMR system (CNS): A new software system for macromolecular structure determination". Acta Crystallogr 1998, D54:905-92I.

46. Jones TA, Zou JY, Cowan SW, Kjeldgaardet M: "Improved methods for building protein models in electron density maps and the location of errors in these models". Acta Crystallogr 1991, A47:1 10-119.

47. Read RJ: "Improved Fourier coefficients for maps using phases from partial structures with errors". Acta Crystallogr 1986, A42:140-149.
Publish with BioMed Central and every scientist can read your work free of charge

"BioMed Central will be the most significant development for disseminating the results of biomedical research in our lifetime. "

Sir Paul Nurse, Cancer Research UK

Your research papers will be:

- available free of charge to the entire biomedical community

- peer reviewed and published immediately upon acceptance

- cited in PubMed and archived on PubMed Central

- yours - you keep the copyright
BiolMedcentral 